\title{
Ilustraciones del 'Quijote' utilizadas en muebles a finales del siglo XIX
}

\author{
María Paz Aguiló Alonso*
}

La narración de episodios continuados de una misma historia o referidos a diferentes momentos de la vida u obras de un mismo personaje es común a la historia del arte y a la literatura desde la Antigüedad. Esculpidas en las columnas conmemorativas o en los frentes de los sarcófagos, a veces acompañadas de breves textos, han permitido que permaneciesen en la memoria, temporalmente oscurecida, los acontecimientos, las hazañas de determinados personajes realizados con la intención de verse perpetuados en el tiempo con diversos sentidos: enseñanza, ejemplo, simple recuerdo, entretenimiento o curiosidad. Algo parecido representaban los retablos medievales, en los que la narración tenía un claro sentido de adoctrinamiento mediante la única herramienta entonces conocida: los distintos cuadros, pintados o esculpidos seguían una coherente lectura visual, que en muchos casos, al desmembrarse, perdieron su legibilidad consustancial. Del mismo modo los romances como poesía narrativa con una temática, caballeresca o hagiográfica, se ponen de moda y aparecen en el siglo XVI impresos en pliegos y colecciones. Esta es una de las soluciones más usuales adoptada en el Renacimiento para ayudar a la comprensión de las imágenes transmitidas. Al igual que las imágenes, el formato de los libros constituía desde el siglo XVI otro aspecto expresivo que complementaban los textos ${ }^{1}$.

En este año que se celebra el cuarto centenario de la publicación del "Quijote", queremos contribuir de algún modo a esta efeméride presentando

* Instituto de Historia, CSIC.

1. Los libros de caballerías eran libros grandes, en formato folio, que tenia la misión de atraer la atención del comprador, aspecto que recoge LuCía MeGías en Imprenta y libros de caballerías. Ollero \& Ramos. Madrid 2000, haciendo suyas las palabras de Moll (1992:18-19) 
una serie de reproducciones de escenas de la obra cervantina reunidas en muebles construidos en torno a 1900, hasta ahora desconocidos, que vienen a sumarse al ingente elenco iconográfico del Quijote. Es conocida la utilización de múltiples episodios de la obra cervantina desde el siglo XVIII en tapicerías, sobre todo las series dibujadas por Coypel o Houasse tejidas en los Gobelinos, los de la fábrica de Santa Bárbara sobre cartones de Procaccini o los italianos sobre los de Giusepe Bonito, todos ellos en la primera mitad del siglo. Igualmente conocida es la utilización de las estampas de Coypel en vajillas orientales de porcelana azul y blanca producidas en Jindezhen y en Cantón con menor destreza técnica, introduciendo motivos locales ${ }^{2}$, en la cerámica de Alcora y del Buen Retiro y también presente en las vajillas de Moustiers y en la loza inglesa a finales del siglo XIX, siguiendo las estampas de los más célebres ilustradores de las abundantes ediciones quijotescas, e incluso en la Exposición del Tercer Centenario del Quijote en 1905 se presentó una batea mejicana con los mismos temas ${ }^{3}$. Fue Givanel quien en 1946 recogió en su obra Historia gráfica de Cervantes y del Quijote, más de doscientas páginas dedicadas a lo que llamó "El "Quijote del Pueblo" en muy diferentes soportes, desde abanicos a papel picado para vasares y billetes de tranvía. Actualmente se está llevando a cabo una importante revisión de los diversos fondos con motivo del cuarto centenario ${ }^{4}$. En 1994 la exposición El mundo literario en la pintura del siglo XIX del Museo del Prado puso de relieve la exaltación del autor a través de alegorías triunfales propias de la visión romántica de la segunda mitad del siglo XIX. Juan Francés Mexía, Manuel García Hispaleto, Sanchez Pescador, Pedro González Bolivar o Miguel Jadraque, recorrieron las páginas de la novela, ilustrando distintos episodios en cuadros que, en general, les proporcionaron abundantes medallas en las distintas exposiciones nacionales de Bellas Artes. Para su realización utilizaron, como es fácil de rastrear ediciones ilustradas casi siempre a partir de la parisina de 1838 con dibujos de Johannot y sus adaptaciones españolas. Así La Edad de Oro, el Entierro de Crisóstomo, el Discurso de las armas y las letras, la presentación de

2. KRAHE, Javier "Miscelánea gráfica cervantina en la Biblioteca del Cigarral del Carmen. Coypel, Vanderbank y Hogarth" Imágenes del Quijote. Modelos de representación en las ediciones de los siglos XVII al XIX. Museo Nacional del Prado, The Hispanic Society of America y Real Academia de Bellas Artes de San Fernando. Calcografía Nacional. Madrid, 2003, pp. 55-71.

3. Catálogo de la exposición celebrada en la Biblioteca Nacional en el tercer centenario de la publicación del "Quijote" el año de 1905, sin índices ni referencias a las láminas. Algunas piezas han sido estudiadas posteriormente en La porcelana del Buen Retiro (1760-1808), Catálogo Exposición Museo Arqueológico Nacional 1999. Para la cerámica española véase C. MAÑUECO "El "Quijote" en el Buen Retiro" en la exposición El Quijote en la cerámica española. Un avance de la misma referido a las lozas de Talavera en Antiquaria $\mathrm{n}^{\circ}$ 241. Septiembre 2005.

4. Givanel MAS, Juan, Ed. Plus Ultra. Madrid 1946. Exceptuando por supuesto los cromos aplicados a cajas de cerillas, diapositivas, sellos de correos, naipes botellas etc que proliferaron en España en la década de los veinte, momento de auge del que se ha venido en llamar "estilo español antiguo". Todo ello queda excelentemente ilustrado en el Proyecto de Iconografía Popular de Don Quijote de la Mancha www.uclm.es/ceclm/CentenarioQuijote/albumes.htm. y en las diversas exposiciones que se están llevando a cabo a lo largo del año 2005.

ANALES CERVANTINOS, VOL. XXXVII, PP. 209-223, 2005. ISSN: 0569-9878 


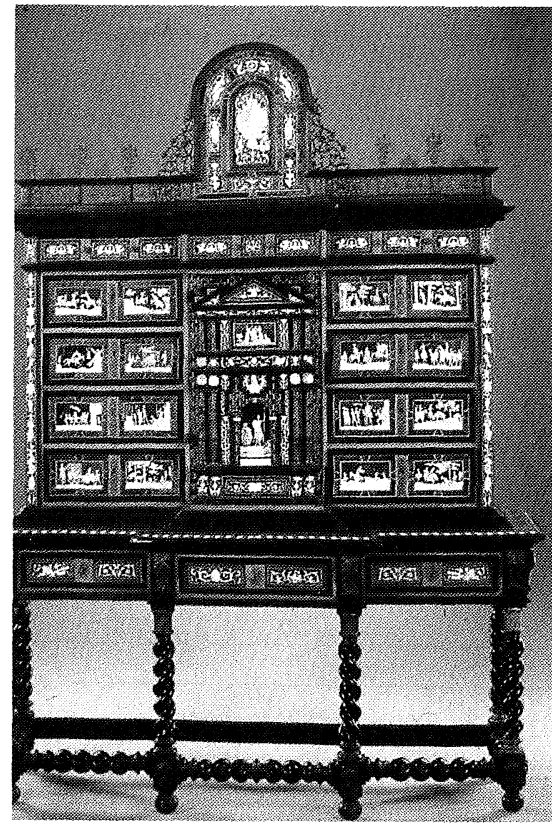

Figura 1. Escritorio con escenas de El Quijote. Países Bajos. ca. 1900-1920. Colección particular.

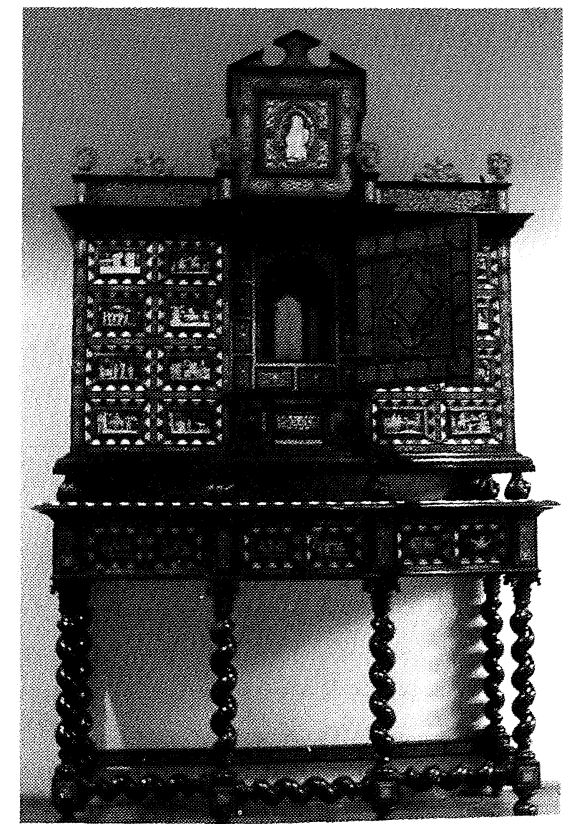

Figura 2. Escritorio con escenas de El Quijote. Países Bajos. ca. 1900. Alcalá de Henares. Casa Natal de Cervantes.

Dorotea, la Visita del cura y barbero a don Quijote, el Ataque a los disciplinantes o la Salida de don Quijote encantado de la venta son algunas de las escenas más representadas.

El mismo interés de revalorización de lo hispánico llevó de un modo similar y en fechas cercanas, finales del siglo XIX, a la realización de algunos pocos muebles, esencialmente bargueños, cuya disposición de numerosos espacios planos en los frentes de las gavetas, se considero idónea para representar una serie de escenas, que permitían recorrer los principales episodios de la inmortal obra. Junto a los dos ejemplares ya conocidos expuestos en la Casa Natal de Cervantes en Alcalá de Henares (Fig.2) ${ }^{5}$, presentamos otros dos, menos conocidos. Hay que hacer constar que ninguno de ellos es de fabricación española, pero que están insertos en el estilo español, tomando las características de uno de nuestros muebles más representativos, el escritorio del

5. Ambos son depósito del Museo Nacional de Artes Decorativas (Inventario $\mathrm{s} / \mathrm{n}^{\circ}$ ). Responden a un tipo generalizado a partir de finales del siglo XVII utilizando la técnica de parte y contraparte, denominada como Boulle - nombre del ebanista francés que más la popularizó- a base de recortar chapas en dos materiales distintos, carey y marfil; en este caso se consiguen dos chapas idénticas pero una en positivo y otra en negativo, las que aplicadas sobre las superficies de los muebles, producen efectos completamente distintos. 
Figura 3. Escritorio con escenas de El Quijote. Italia. Ca. 1900-1920. Madrid. Fundación Lázaro Galdiano.

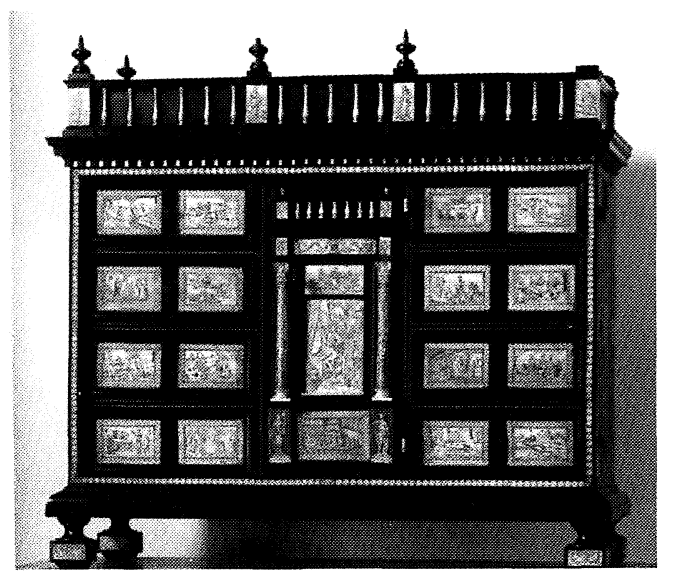

siglo XVII, conocido popularmente como "bargueño"6. Los tres primeros responden a modelos flamencos (fig. 1 y 2) mientras el último parece estar más cerca de la producción napolitana, si bien en las fechas en que fue realizado -primer tercio del siglo XX- el mercado de los falsos y falsos históricos estaba suficientemente extendido por Europa y también pudiera haberse hecho en los Paises Bajos (fig 3) 7 .

El primero, procedente del mercado de arte, está chapeado en ébano, carey y marfil, clasificado como hispanoflamenco y fechado en torno a 1870 "al modo del siglo XVII"8, presenta un importante numero de aspectos iconográficos para resaltar su españolidad: un ático centrado en una balaustrada de bronce dorado preside la composición con las armas reales españolas incluido el Toison de Oro. Bajo tres cajones estrechos decorados con medallas con bustos en marfil, se disponen dos cuerpos laterales de cuatro cajones cada uno, con dos placas cada uno con escenas del "Quijote", flanqueando una gran portada central de tipo arquitectónico adintelada entre parejas de columnas con atico y frontón: sobre un fondo de concha imita el almohadillado de los sillares. Tras la puerta se abre un interior recubierto de espejos teselados con arquerías sobre columnillas salomónicas simulando marfil, remedo de los llamados "frontispicios" flamencos del siglo $\mathrm{XVII}^{9}$. Todo el mueble asienta sobre un soporte chapeado en nogal con tres

6. Para el estudio estilístico de este mueble y el uso de la palabra bargueño para su denominación véase Aguiló, M.P. El mueble en España. Siglos XVI-XVII. CSIC y Ed Anticuaria, Madrid, 1993.

7. Este último es objeto de un estudio pormenorizado en la revista Goya.

8. Sotheby's London 9-12 June 1989. Lote 200. Precio de salida 20000-30000 libras. Medidas: $183 \times 183 \times 62 \mathrm{~cm}$.

9. Interiores muy elaborados con puntos de vista convergentes a un punto, reflejado por espejos situados en diferentes ángulos, y con variedad de "secretos" en lugares inverosímiles, que contribuían a la teatralidad barroca de este tipo de muebles. Para ellos véase FABRI, Ria "De 17de-eeuwse 


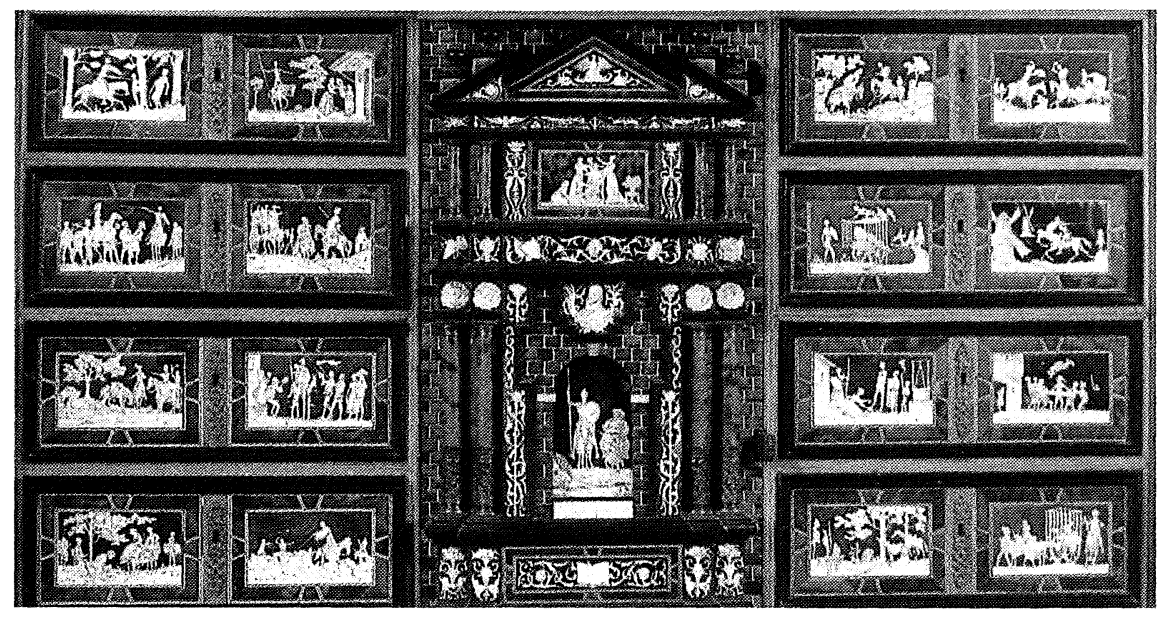

Figura 4. Escritorio flamenco: Frente de gavetas.

cajones, sobre patas ebonizadas torneadas en espiral unidas por chambranas. El tipo de soporte, las dimensiones y la estructura de interior complementada con el "frontispicio" responde al modo de hacer flamenco desde el siglo XVII, retomado en el siglo XIX. de carey a modo de sillares, disponiéndose medallas y placas alusivas.

En el frontón del frente se dispone la efigie de Cervantes. Al interior, una placa similar al resto representa los dos personajes principales, Don Quijote y Sancho; en el ático se dispone otra placa representando la escena en la que las mozas desarmando a don Quijote [I:2 ] y en el basamento, entre los pedestales de las columnas, un libro abierto, claro homenaje a la obra cervantina.

Las placas tal y como estan situadas en el mueble (fig. 4), comenzando por la izquierda representan los siguientes episodios: Don Quijote socorriendo a Andres y llegada a la venta; Encuentro con los galeotes y Encuentro con los mercaderes junto con Fin de la aventura de Clavileño y don Quijote con la bella cazadora; Sancho presentando a don Quijote a la encantada Dulcinea junto a la Batalla con el rebaño de ovejas. En el lado derecho comparten frente la pelea con el vizcaino y la aventura con el Caballero del Bosque; don Quijote se enfrenta con el león enjaulado junto con el ataque a los molinos; don Quijote armado caballero y el manteamieto de Sancho ocupan otro frente y, por último, la pelea de Sancho con don Quijote y la Vuelta a casa en la jaula.

La placa central representando al héroe y su escudero (fig. 5), sigue muy de cerca el conocidísimo grabado de Doré (fig. 6).

Antwerpse kunstkast. Typologische en historische aspecten" Verhandelingen van der Koninklijke en Schone Kunsten van België. Jaargang 531991 y AGUILó, Ma Paz Mueble en España. Siglos XVI-XVII. Madrid, 1993. 


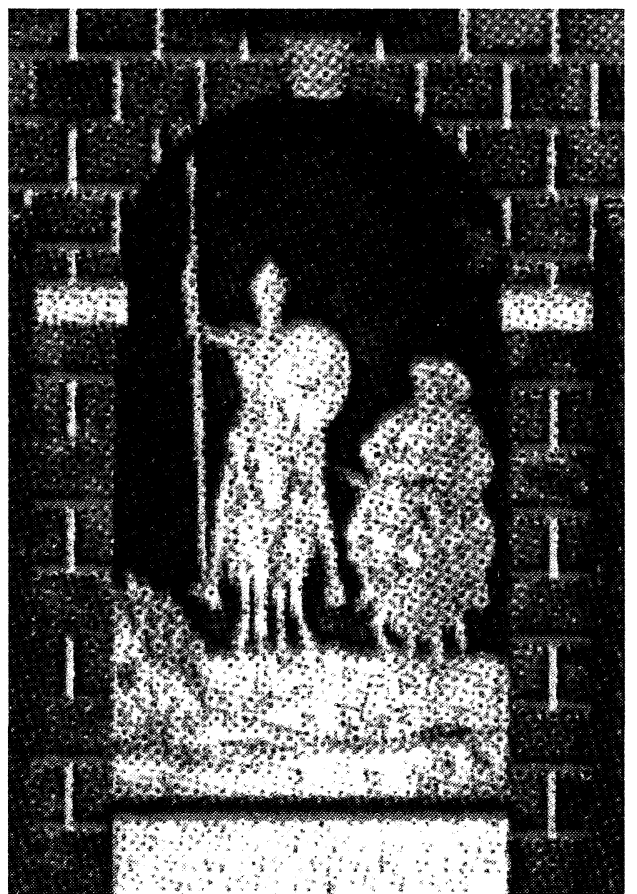

Figura 5. Detalle central. Portada central del escritorio flamenco.

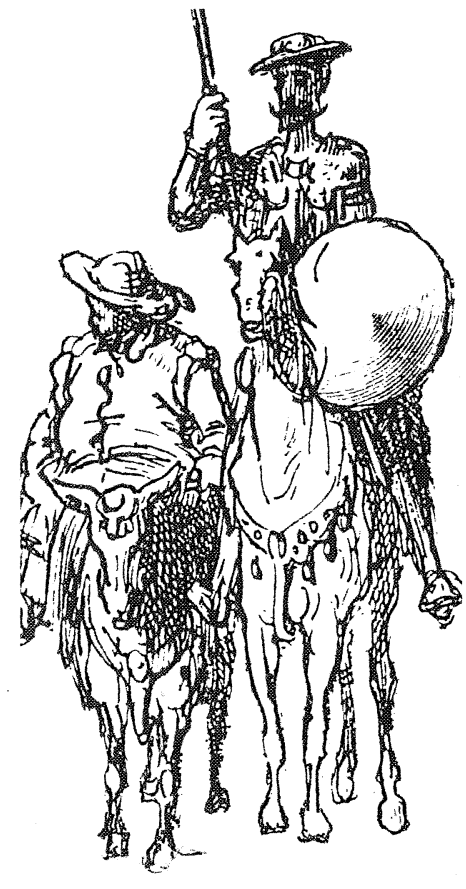

Figura 6. Gustavo Doré. Don Quijote y Sancho. Para la Edición de Hachette. París 1863

La escena se inserta en una de las muchas de las salidas de ambos personajes, quizás la que más veces se ha ilustrado, bien la Segunda salida [I:9] o Don Quijote y Sancho parten al alba buscando las riberas del Ebro [II:28], a partir de la estampa dibujada por José del Castillo y grabada por Fernando Selma (Fig. 7) o la del mismo Doré, que escenifica como nadie la alegría de los dos personajes al salir en busca de nuevas aventuras. Muy cercana es también la cromolitografía que Jose Luis Pellicer realizó con Ricardo Balaca para la edición de Montaner y Simón de 1880, en la que se muestra que ambos habían estudiado los mismos modelos anteriores para formular su obra (fig. $8)^{10}$, pero con la que realmente tiene un parecido mayor es con la escultura de Lorenzo Coullaut Valera de la madrileña Plaza de España convertida en el referente universal de la pareja (fig. 9). Collault recibió el encargo a partir de 1915, cuando el Ayuntamiento de Madrid decidió erigir el monumento a Cervantes para conmemorar el tercer Centenario de la segunda parte del Quijote. Los bocetos fueron realizados en 1914, manejando para ellos estampas sueltas como las citadas de Castillo y Selma, que fijan de un modo perfectamente 


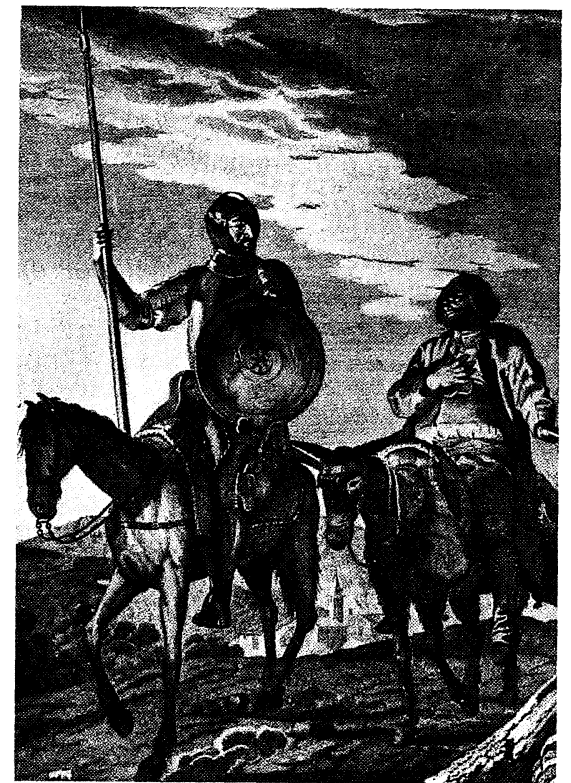

Figura 7. Dibujo de José del Castillo. 1780. Madrid Biblioteca Nacional.

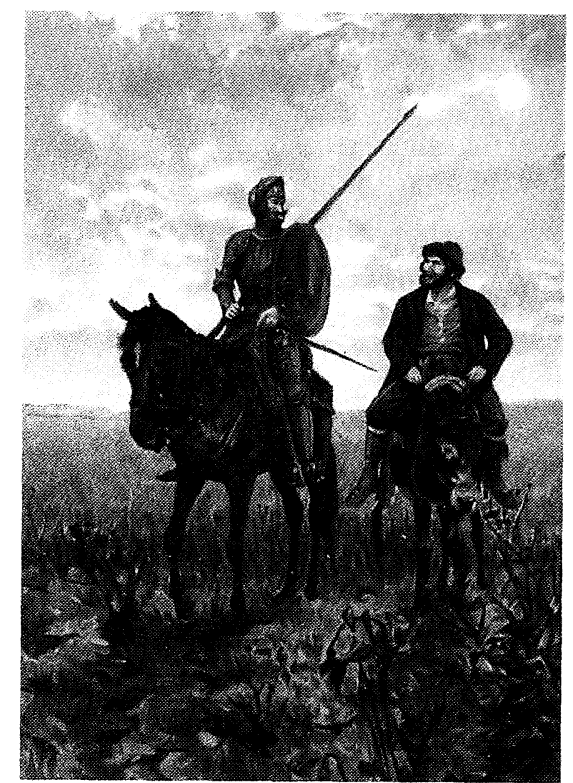

Figura 8. Cromolitografía de José Luis Pellicer para la edición de Montaner y Simón. Barcelona 1880.

clásico la iconografía de la pareja, pero la obra definitiva no se concluyó hasta $1930^{11}$, lo cual de algún modo contradice la fecha propuesta para la realización del mueble cincuenta años antes. La vista lateral del monumento prueba que Collault había visto incluso la portada de la primera edición inglesa de 1618 (fig. 10).

Tampoco es extraña su colocación a modo de portada en el centro del mueble para su mejor identificación, aunque es ciertamente un concepto muy moderno y de algún modo retórico. En ese lugar, habitualmente destinado a la imagen más relevante del frente, en el siglo XVII se solía colocar la personificación de una virtud y en España era muy frecuente que fuera Hércules como caballero luchador protector de damas y desvalidos, realizado como figura exenta en bronce o metal dorado sobre todo en los escritorios realizados a la flamenca sobre fondos de carey.

Repasando las escenas representadas y pese a la dificultad de lectura por la calidad de la fotografía, hemos intentado buscar los grabados y/o las

11. Sobre las vicisitudes del proyecto para el monumento haciéndolo coincidir con el centenario de la edición de la segunda parte del Quijote en 1915, véase $M^{a}$ Socorro SALVAdOR PRIETO "El monumento a Cervantes en la Plaza de España" en Cinco siglos de arte en Madrid ( $X V-X X)$. III Jornadas de Arte. CEH (CSIC) 1991 p.153-162. En la reciente exposición El Quijote, Rodriguez Marín y el CSIC (CSIC 2005), la sección VIII muestra toda la documentación sobre el monumento, conservada en el Archivo Rodríguez Marín del CSIC 


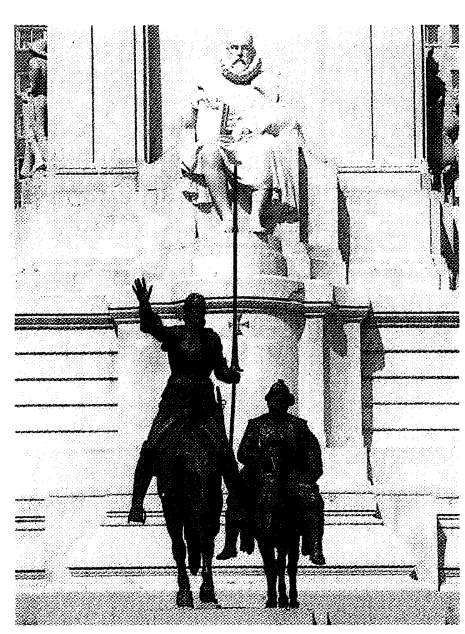

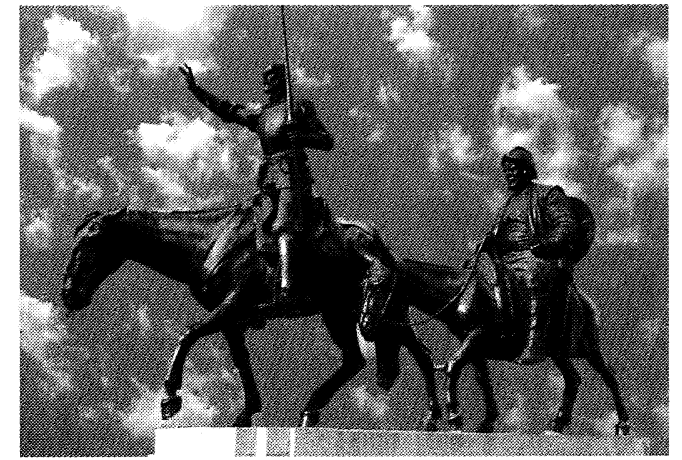

Figura 10. El mismo: vista lateral.

Figura 9. Lorenzo Collaut Valera. Monumento a Cervantes. 1930 Madrid. Plaza de España. Detalle Vista frontal.

ediciones que les sirvieron de inspiración, sin entrar en detalle sobre la calidad de ejecución, por los motivos expuestos.

En la llegada de don Quijote a la venta se escenifica el propio título del capitulo "Llegando a la venta, don Quijote se dirige a dos mozas "destas que llaman del partido", las cuales iban a Sevilla con unos arrieros que en la venta aquella noche acertaron a hacer jornada", explicándolas su adhesión a las reglas de caballería [I:2]. Ante el asombro o espanto de aquellas, y su intento de retirada, don Quijote se afirma en su papel "no fuyan vuestras mercedes ni teman desaguisado alguno". Se trata de una escena mal compuesta centrada por un árbol frondoso, dejando apenas espacio para el caballero que se acerca, apenas un palillo sobre el caballo, con otro arbolito a su izquierda. Quizás la composición se hizo así para hacer juego con su pareja: Don Quijote socorriendo a Andrés, en la que el árbol central con el muchacho atado quiere ser el centro de la composición, mientras a un lado el caballero reprende a Juan Haduldo al lado contrario. Tampoco en esta el grabador ha estado muy acertado en la representación de las figuras.

El segundo cajón presenta también dos episodios no consecutivos: el encuentro con los galeotes [I:22] y con los mercaderes [I:4]. Ambas escenas compensan el abundante número de figuras representadas, ocupando prácticamente todo el espacio, mejor resuelto en la segunda, al formarse un grupo compacto a un lado, acercando a primer plano a los dos personajes principales. Para la primera parece haberse utilizado el dibujo Doré para el mismo episodio (Fig. 11), aunque también podría tratarse de el encuentro de don Quijote con el escuadrón del rebuzno [II:27], dada la abundancia de personajes y la presencia de gallardetes, banderolas, lanzas y todas suertes de armas.

Si siguieramos cronológicamente el orden establecido en la novela, los dos frentes referidos presentan sus escenas cambiadas de lugar. Siguiendo ese mismo orden la lucha con el vizcaíno [I:4] y la aventura con el caballero del 


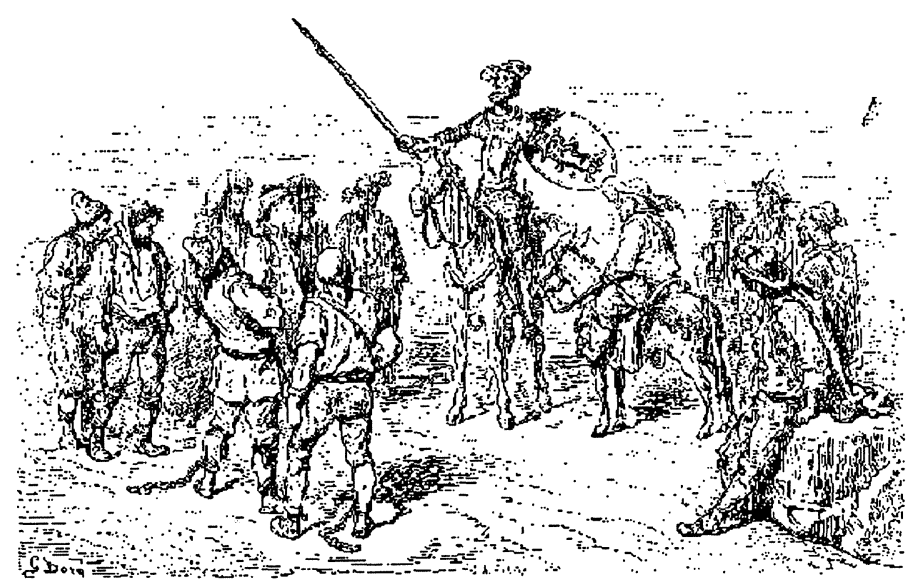

Figura 11. Gustavo Doré Encuentro con los galeotes.

bosque [II:13] deberían seguir la narración, sobre todo la primera, en la que se advierte el coche a la derecha (fig. $\left.12^{a}\right)^{12}$. En este caso se han querido representar juntas dos escenas con dos jinetes enzarzados en diferentes modos de lucha, con lanza y con espada, para los que hay muchas imágenes previas, comenzando por el grabado de José López Enguídanos para la edición de 1797 de la Imprenta Real, repetida en la edición de París de 1807 (fig. 12) o la de Clemencin de 1833, llegando en similar disposición a la más popular de Pahissa para la de Ambos Mundos de Barcelona 1916.

La misma tónica de adecuación de escenas por composiciones afines se observa en las siguientes entre las que se inserta un episodio tan tardío como la aventura de Clavileño Cree don Quijote atravesar las esferas del aire y del fuego sobre el Clavileño alígero [II:41], escena que tan bellamente recreara Antonio Carnicero para la edición de la Academia de 1780.

El episodio de Sancho presentando a don Quijote a la encantada Dulcinea [II:10] cae en idéntico convencionalismo paisajístico de las anteriormente descritas, con un árbol, cuya espesa copa se alarga por un lado para adecuarse al marco de la estampa. Parece claro que el grabador conocía la edición de la Academia. Como recogen las instrucciones redactadas para la lámina correspondiente, denominado entonces "el encanto de Dulcinea" para el escenario "se figurará un campo espacioso y llano, a un lado un bosque y a lo lexos el lugar del Toboso; Sancho de rodillas, don Quixote estará también al lado de Sancho puesto también de rodillas en ademán de estar callado como admirado..."13 Junto a este se representa el

12. La colocación de los cajones es aleatoria, ya que es perfectamente reversible. No así la colocación de dos escenas en un mismo frente, al ir las placas pegadas.

13. Asuntos para las láminas que se han de poner en la obra de Don Quixote [RAE, leg. 302 n5] publicados por J. Blas y J. M. MATILla "Imprenta e ideología. El Quijote de la Academia, 1773-1780" en Imágenes del Quijote. Madrid, Museo del Prado y Calcografía Nacional, 2003, anexo 2. 


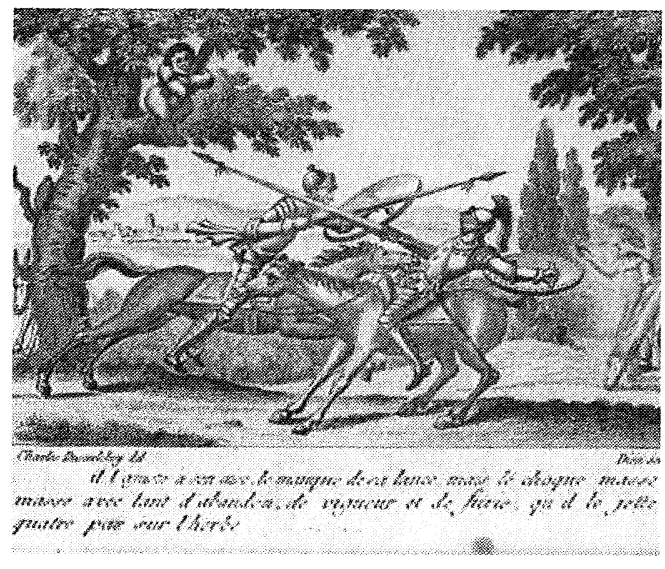

Figura 12. Aventura del caballero del bosque. Ed. París 1808 .

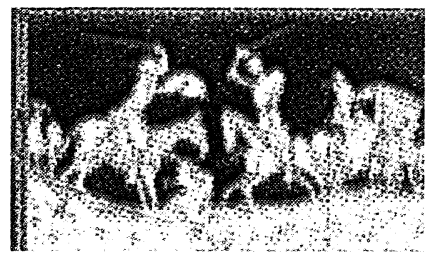

Figura 12a. Pelea con el vizcaíno.

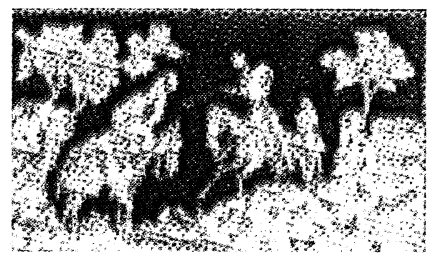

Figura 12b. Lucha con el caballero del bosque.

combate de las ovejas, disponiendo a un don Quijote alanceando a diestra y siniestra; aunque fácil de reconocer es torpe en su ejecución y su colocación junto al episodio anterior es también aleatoria. En otro frente aparece la aventura de los leones [II:17].

"en el espacio que tardó el leonero en abrir la jaula primera estuvo considerando don Quijote si sería bien hacer la batalla antes a pie que a caballo, y al fin se determinó de hacerla a pie, temiendo que Rocinante se espantaría con la vista de los leones. Por esto saltó del caballo, arrojó la lanza y embrazó el escudo y desenvainando la espada, paso ante paso, con maravilloso denuedo y corazón valiente, se fue a poner delante del carro encomendándose a Dios de todo corazón y luego a su señora Dulcinea"

En este caso también se sigue casi al pie de la letra las instrucciones para la edición de la Academia: "Ponen a don Quijote delante de un león y este casualmente se queda en su jaula", como figura en la estampa de Carnicero en la Hispanic Society de Nueva York ${ }^{14}$, "con Sancho huyendo en su rucio y otro hombre a caballo y el carretero también huyendo", sin adoptar el aspecto jocoso que Doré recreó y fijó, siguiendo el texto cuando "el león volvió las espaldas y enseñó las partes traseras a Don Quijote", y junto a él la aventura de los molinos [I:8], en el momento del ataque, siendo aquí más grande el caballo que el molino en primer término.

El penúltimo cajón presenta dos episodios más cercanos entre sí, pertenecientes a los primeros capítulos de la primera parte: Don Quijote armado

14. Imágenes 1993 cat. № 82 . 


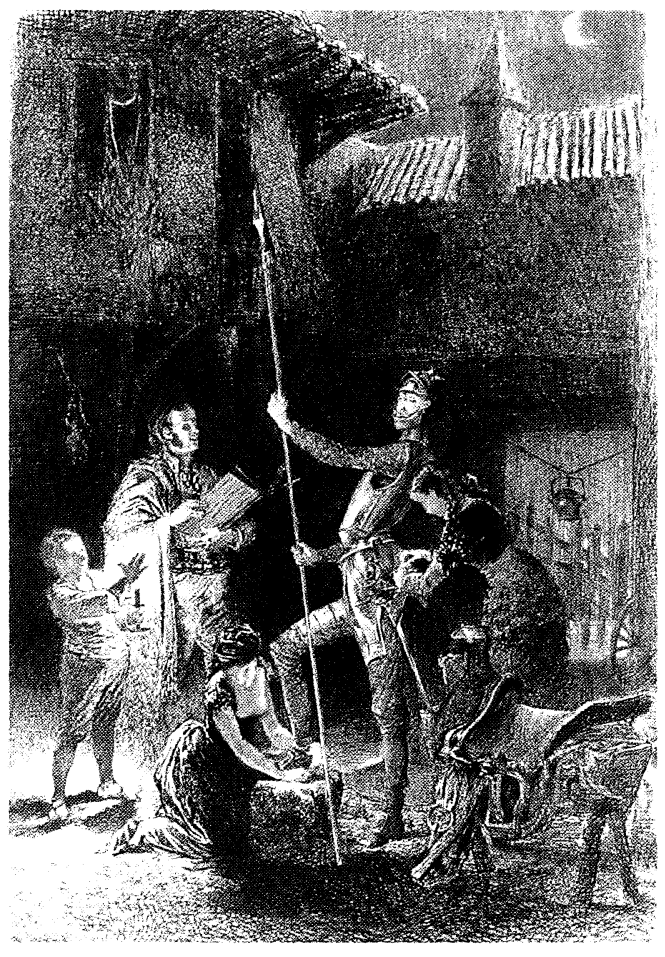

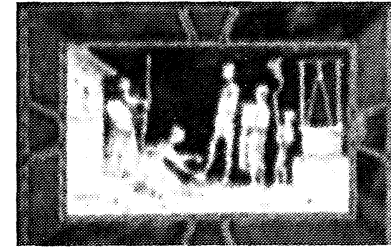

Figura 13a. D. Quijote armado caballero.

caballero y el Manteamiento de Sancho. El primero sigue la estampa de Adolphe Lalauze de la edición de Paterson, (Edimburgo 1879-84) (fig. 13) con la misma expresión exaltada y elocuente del tema, destacando el pozo como elemento esencial en el patio de la venta donde don Quijote debía velar sus armas, la figura del ventero con el libro en la mano y las doñas ayudándole ${ }^{15}$.

El manteamiento de Sancho recoge una de las versiones más comunes a partir de la edición de la Imprenta Real de Madrid de 1797 (fig.14), significándose bien la pared de la venta con la figura de Maritones destacándose en el dintel, solo seis personajes y la cabeza y lanza de don Quijote tras la valla, modo simple de representación que retoma Johannot para la edición de Paris de 1838. La disposición apaisada quedó fijada definitivamente en ediciones más modernas, como la de Montaner de Barcelona de 1880-83 (fig.15) ${ }^{16}$, edición fiel a la categoría de "libro de entretenimiento", según la clasificación iconográfica de Lucía Megías ${ }^{17}$.

15. Ibidem p.332.

16. Blas y Matilla op. cit 97 .

17. "El manteamiento de Sancho Panza [I:XVII]: lectura de un episodio cervantino a través de algunos de sus grabados" en Don Quijote ilustrado. Don Quijote als leser und die Spanische Renaissance. Edición de Javier Gómez-Montero, Inés M. Martín y José Ramón Trujillo. Forschungsstelle Ceres. Christian-Albrechts-Universität zu Kiel. Sial/Fugger Libros. 2003, pp. 67-96. 


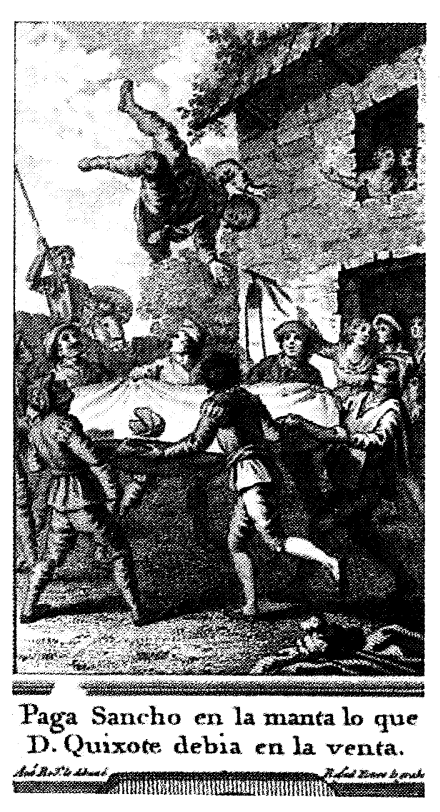

Figura 14. Manteamiento de Sancho Imprenta Real 1797.

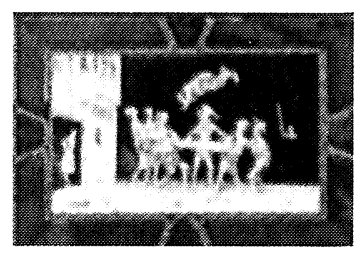

Figura 14a. Manteamiento de Sancho.

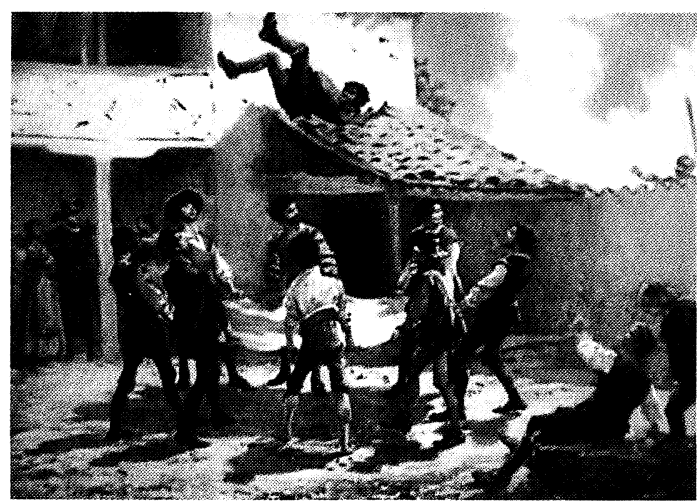

Figura 15. Manteamiento de Sancho Montaner y Simón 1880

En la última gaveta aparecen representadas otras dos escenas. Mientras la segunda es claro el episodio de Don Quijote de regreso a la aldea en la jaula en el carro de bueyes [I:47-48], el de la izquierda con las dos caballerías atadas a sendos árboles y los personajes en el suelo, con otras dos figuras, puede identificarse con el inicio del capítulo lo que sucedió a Don Quijote yendo a Barcelona [II:60] al advertir los cuerpos de los bandoleros colgados de los árboles y su inmediato encuentro con Roque Guinart.

También el episodio de las mozas desarmando a don Quijote de la sobrepuerta (fig.17), sigue un curioso modelo, el de la edición de de Bossage y Maldun de Paris 1814 (fig.16) ${ }^{18}$ tomada de las ediciones españolas de la Academia de 1780 y 1782 . Esta escena no es una de las más representadas en las diversas ediciones más populares, por lo que en principio podía llamar la atención su disposición en el mueble en lugar preeminente. La comparación con otros ejemplares en los que se disponen también escenas centrales, como el del museo Lázaro Galdiano, nos induce a pensar que su colocación en este caso, no parece responder a ninguna finalidad predeterminada, sino que posiblemente, la forma de la composición piramidal no se adecuaba con el resto, todas desarrolladas de un modo lineal y por ello se prefirió colocarla en ese lugar.

18. L'ingenieux chevalier don Quixote de la Manche a Paris, chez Th.Desoer 1821. Dibujada por Deverie, tomo 3 p. 315 , grabado por Simonet jeune.

ANALES CERVANTINOS, VOL. XXXVII, PP. 209-223, 2005. ISSN: 0569-9878 


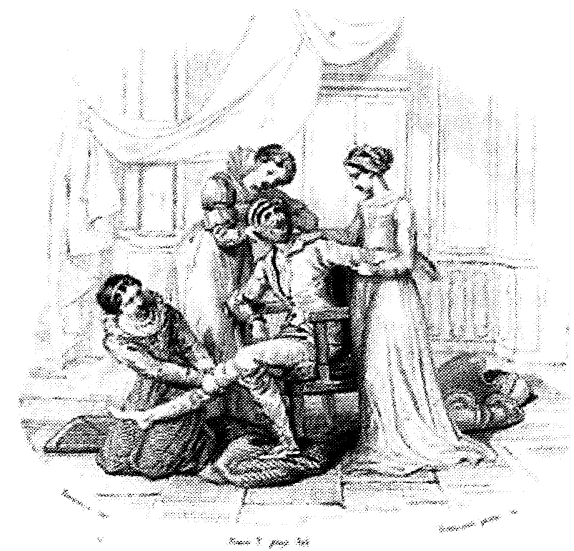

Figura 16. Las mozas desarman a D. Quijote. Grabado de la edición de Bossage y Maldun. París 1814.

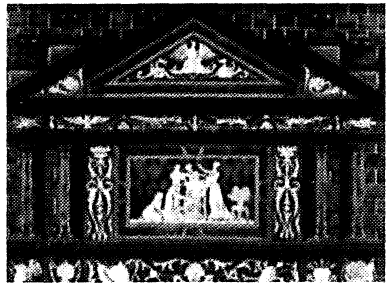

Figura 17. Las mozas desarman a D. Quijote.

Lo primero que se advierte es que casi todas las escenas se desarrollan al aire libre, seis entre árboles, cuatro con referencia espacial de edificación lateral, el patio de la venta y el resto destacando simplemente las figuras en marfil grabado sobre carey liso, incluída la última que comentamos, sin ningún referente espacial. Deliberada o casualmente no se representa ningún episodio en interiores, ni aún los más populares como el de los cueros de vino, o la disputa sobre el yelmo de Mambrino, escenas que se desarrollan en el interior de la venta en la primera parte o las que tienen lugar en en el palacio de los duques en la segunda. Parece como sí, con la primera parte y poco más, el grabador obtuvo el suficiente número de placas para ornamentar el mueble, sin preocuparse por la hilazón de lo representado.

La utilización de estampas procedentes de las ediciones francesas anteriores a 1836 no muy comunes, como la del desarme o la del episodio del Caballero del Bosque, la referencia en detalles ornamentales a las ediciones canónicas españolas de finales del siglo XVIII, como los ya comentados al repasar las distintas placas, entre las que pueden incluirse la presencia de personajes secundarios con gallardetes o banderolas en varias de ellas, nos induce a conjeturar que el grabador tuvo en la mano un repertorio de estampas bastante amplio, y relativamente más escogido que las ediciones popularizadas de mediados de siglo XIX. Incluso llega a utilizar medallas, como la efigie de Cervantes, entre grandes palmas tan característica de finales del siglo XVIII, como común a lo largo del siglo siguiente.

Hay en este frente, sobre todo en la elección de los temas, un deseo de presentar solamente los más populares, sí, pero ninguno que ridiculice más allá de un simple enunciado, la figura de don Quijote. A diferencia por ejemplo de Doré, o incluso del mismo Johannot, no aparecen los episodios que le presentaban como figura ridícula, colgado, apaleado, ni su derrotas, caídas, 


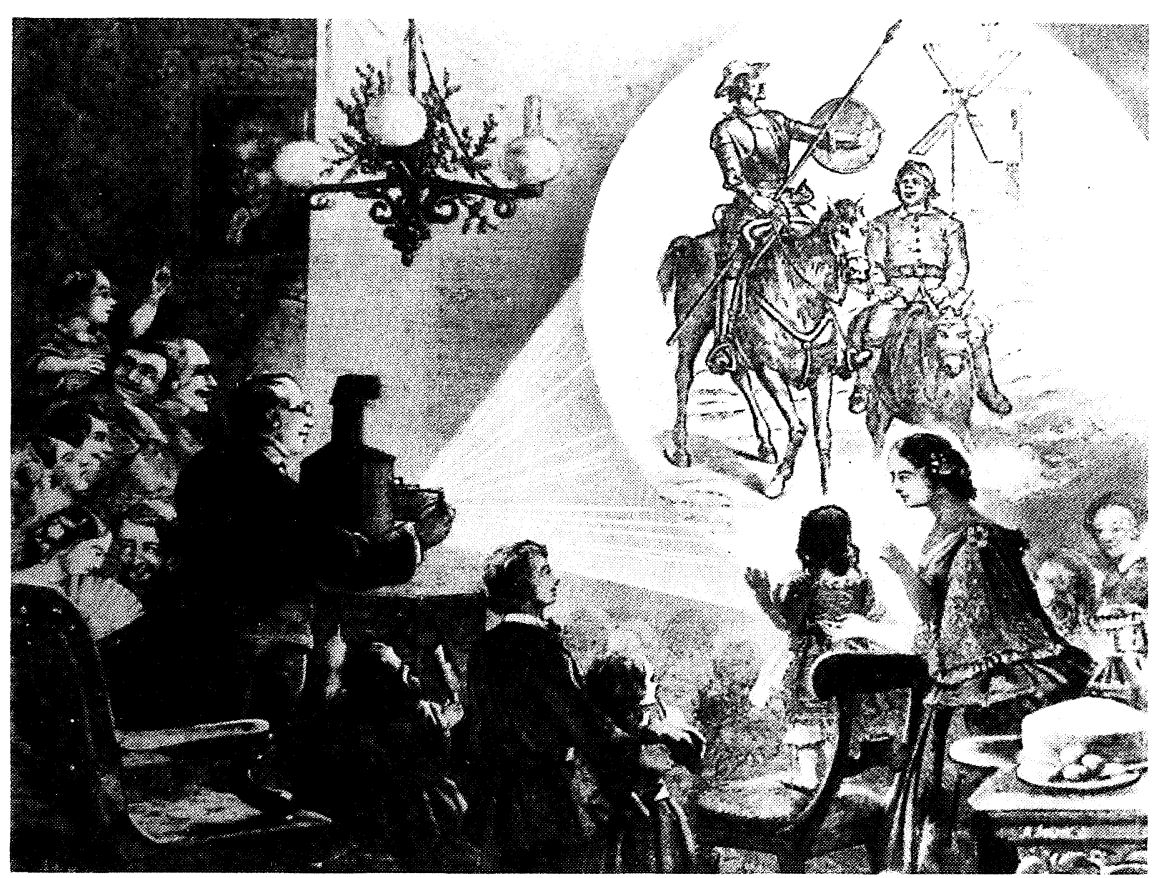

Figura 18. Sesión de linterna mágica. Litografía francesa segunda mitad XIX (de Givanel).

convalecencias o muerte, ni siquiera en los que se destacan sus más cercanos personajes, que intentan recomponer su persona desde la locura, ni tampoco ninguna de la segunda parte con los agridulces episodios en la corte de los duques o en Barcelona. El personaje de don Quijote está resaltado prácticamente en todas las escenas y aunque, como se ha dicho, la colocación de los cajones es susceptible de variación, se percibe el interés por equilibrar ambos lados en cuanto al número de figuras, colocación de la arboleda, es decir vacíos y plenos, que de alguna manera preocupó al grabador. Falta también en este mueble una de las imágenes definitoria de la obra: la primera escena del libro con don Quijote leyendo libros de caballerías, que sí se encuentra sin embargo en los otros muebles a los que se ha hecho referencia al principio: centra la composición en el mueble de la Fundación Lázaro, copiando la famosa estampa de Gustavo Doré o repite el modelo de Daumier en los dos ejemplos de la Casa Natal de Cervantes, añadiendo una mesa a un lado y un armario con libros al otro, alargando así la composición. En estos últimos muebles se pueden observar escenas que incluyen pasajes de la estancia en casa de los duques con don Quijote bailando, pero tan mal realizados que dificulta su lectura y la búsqueda de las ilustraciones empleadas, cosa que es más manifiesta si cabe en el segundo ejemplar, el negativo, en el que las placas están practicamente emborronadas. 
Al igual que estos últimos, el mueble que comentamos es una representación amable, de revalorización de las grandes novelas y de los literatos, en la misma línea de la segunda mitad del siglo XIX, en la que aquellas instructivas sesiones de la linterna mágica representaban al autor junto a los principales personajes sonrientes, a la busca de aventuras, con el referente en el mismo plano a la más emblemática de ellas, la de los molinos (fig.18).

\section{Resumen}

El mostrar en el frente de un mueble escenas pertenecientes a una obra famosa constituye una costumbre ya utilizada en el siglo XVII. De los pocos ejemplares conocidos con temas quijotescos -solo cuatro- destaca el que aquí se muestra, producción flamenca posiblemente coincidente con el tercer centenario de la aparición de la obra. Se analizan los temas que aparecen, sus fuentes tomadas de las ilustraciones de diversas ediciones decimonónicas, así como el gusto por la elección de escenas amables, desarrolladas casi exclusivamente en exteriores, que evidencia el afán erudito propio de la época junto al interés por revalorizar un tipo de mueble genuinamente hispánico como es el escritorio.

Palabras clave: Ilustraciones; Quijote; escritorio; “estilo español”.

\section{Sumary}

Different episodes of Don Quixote are shown on the front of drawers of a Flemish cabinet dated at the end of the nineteenth Century. The research of the printed sources used, most of them from English and French editions of the book, and the aparently tendence to choose only pleasant items, always in outdoors scenes, shows the fashionable taste of the "Spanish style" of those days, when the thirth Centenary of the first edition was arriving.

Key words: Book illustrations; don Quixote; cabinet; 'Spanish style'. 